DOI: $10.31168 / 2658-3372.2020 .1 .02$

\author{
МИРОСЛАВ ВЕПРЖЕК \\ Университет Палацкого, Оломоуц, Чехия \\ К ВОПРОСУ О НЕДАВНО \\ ОБНАРУЖЕННЫХ ВЕРСИЯХ \\ ЦЕРКОВНОСЛАВЯНСКОЙ МОЛИТВЫ \\ СВЯТОГО ГРИГОРИЯ
}

Церковнославянскому переводу Молитвы святого Григория я уже посвятил несколько работ (полностью результаты представлены в монографии Vepřek 2013). В итоге этого исследования было установлено, что Молитва была переведена с латинского оригинала, который, вероятно, возник в XI в. в культурной среде пржемысловской Чехии. Аргументы в поддержку этой гипотезы были выдвинуты в первую очередь на основе анализа переводческой техники и лексических параллелей с другими памятниками древнейшей славянской письменности.

Латинская версия молитвы - в большинстве списков названная Oratio sancti Gregorii (рарае) - представляет собой паралитургический текст, очень популярный от раннего Средневековья вплоть до Нового времени на всем христианском Западе. До сих пор известно почти сорок рукописных версий. Существует множество молитв, приписываемых святому Григорию Великому, инципит протографа чешского текста - Domine exaudi orationem meam quia iam cognosco tempus meum proppe esse (вариант: est). Самые старые списки относятся к IX веку: кодекс из монастыря в Теплой (шифр b 9), происходящий из Регенсбурга, в настоящее время находящийся в Национальной библиотеке Чешской республики, 2-й половины IX в.; так называемая Симеонова псалтырь, IX в., из Милана, в настоящее время в Государственной библиотеке в Берлине (шифр Hamilton 552); Zürich Psalter (неполная версия) IX в., Санкт-Галлен, в настоящее время в Центральной библиотеке в Цюрихе (шифр Ms. C 12); The Psalter of Count Achadeus, конец IX в., Франция, в настоящее время в Колледже Корпус-Кристи в Кембридже (шифр MS 272). Для анализа церковнославянского перевода очень важны также рукописи X и особенно XI в., 
хотя речь не идёт о прямых протографах. Наиболее близкой к протографу версией кажется вариант латинской молитвы из рукописи, возникшей около 1040 г. в Рейнланде, а в настоящее время находящейся в библиотеке в Дармштадте (шифр Нs 544). Далее следует назвать две сохранившиеся версии с британских островов - в псалтыри из Бери, Англия, сер. XI в., в настоящее время хранится в Ватикане (шифр Reg. lat. 12), и в так называемом Портифории святого Вульфстана, Англия, сер. XI в., сейчас хранится в Колледже Корпус-Кристи в Кембридже (шифр Мs. 391). Некоторые интересные разночтения, отраженные в церковнославянском переводе, содержит также версия молитвы в Сборнике Оттона III рубежа X и XI вв., который в настоящее время хранится в Баварской государственной библиотеке в Мюнхене (шифр Clm 30111), хотя этот вариант и содержит ряд отклонений от всех прочих текстов латинской традиции молитвы.

Даже такой беглый обзор латинских версий молитвы показывает, что её текстологическое изучение является очень трудной задачей. Более того, в случае паралитургического текста нельзя рассчитывать на наличие канонизированного варианта без большого количества исправлений и промежуточных вариантов, как, например, в случае литургических или библейских текстов. Разница вариантов при этом проявляется и в случае сохранившихся версий церковнославянского перевода.

Предыдущие попытки анализа церковнославянского перевода исходили из двух версий, опубликованных А. И. Соболевским (1905) и Ф. В. Марешем (1979). Первая - из Ярославского молитвенного сборника (XIII век, в настоящее время в Ярославском историко-архитектурном и художественном музее, шифр ЯКМ 1548, далее - J). Вторая из псалтыри XV века (Соболевский её обозначал как «Молдавская псалтырь», в настоящее время - в Москве, Государственный исторический музей, шифр Унд. 1274, далее - М). На основании этих двух версий было подготовлено новое издание текста (параллельно с латинским) по снимкам рукописи из Ярославского сборника.

Практически сразу после публикации моей монографии (2013), текстом Молитвы святого Григория (далее - МСГ) занимались и другие исследователи. Ф. Чайка обнаружил и издал версию молитвы, сохранившуюся в сербскоцерковнославянском списке псалтыри 1573 г., 
хранящемся в Национальной библиотеке в Белграде (шифр Рс 30, далее $-\mathrm{S})$. На основании некоторых текстологических особенностей он выдвинул гипотезу, что МСГ относится к текстам, попавшим с Руси на юг Славии. На еще одну, очень важную, версию МСГ обратил внимание В. Чермак (в 2014 г., в рецензии на Vepřek 2013), который упомянул тот факт, что часть молитвы записана в так называемой Дмитриевой псалтыри (далее - D), которая была обнаружена среди рукописей в монастыре св. Екатерины на Синае в 1975 году и опубликована в 2012 (Miklas et al. 2012). Этим вариантом более тщательно занималась П. Станковска (Stankovska 2016), которая, однако, ни подтвердила, ни опровергла гипотезу Чермака о том, что МСГ могла бы иметь великоморавское происхождение (cp. Čermák 2014: 126).

Распространенность МСГ в Чехии в ХІ в. доказал Т. Микулка (Mikulka 2015), который интересовался текстовыми параллелями другой молитвы чешскоцерковнославянского происхождения, сохранившейся, однако, только в русских списках, - Молитвы к св. Троище. Микулка идентифицировал один краткий текстовый пассаж, который в Мoлитве к св. Троице цитируется, очевидно, из $\mathrm{MC}^{1}$. Еще одну рефлексию мы находим в работах Р. Станкова, который в своем анализе акцентировал прежде всего версию МСГ из «молдавской» псалтыри, и выразил мнение, что молитва происходит с юга Славии, вероятнее всего, из Болгарии (Станков 2016: 196). Его гипотеза, однако, кажется очень малоправдоподобной, прежде всего остается без ответа принципиальный вопрос о мотивации перевода с латыни.

В данной работе я хотел бы, во-первых, отнестись критически к вышеприведенным новым открытиям и гипотезам о МСГ и, во-вторых, включить также в текстологический анализ недавно обнаруженные рукописные версии церковнославянского перевода. Помимо описанных выше версий далее я включаю в анализ до сих пор не изученные варианты молитвы из трех рукописей:

1 T. Микулка в цитируемой статье также обращает внимание на еще одну версию МСГ из рукописи Троице-Сергиевой лавры 779 XVI в., однако я её в дальнейший анализ не включаю. 
1. версия из сербскоцерковнославянского молитвенного сборника XVII века из фонда Хиландарского монастыря (шифр 362), МСГ находится на листах $58 \mathrm{~b}-60 \mathrm{a}^{2}$, далее в тексте под литерой $\mathrm{H}$;

2. русскоцерковнославянская версия из сборника конца XVI века, хранящегося в Российской национальной библиотеке в Санкт-Петербурге, шифр Погод. 1594 (ср. Бычков 1880: 242-257), ${ }^{3}$ рассматриваемая молитва находится на листах $15 \mathrm{~b}-17 \mathrm{a}$, далее в тексте под литерой $\mathrm{P}$;

3. русскоцерковнославянская версия из так называемой Псалтыри владыки Кассиана Рязанского, рукописи середины XVI века, хранящейся в библиотеке РГАДА, шифр Обол. 78; МСГ находится на листах 1002b-1004b, далее в тексте под литерой R.

Первым принципиальным вопросом является то, все ли варианты молитвы восходят к одному и тому же гипотетическому архетипу. Учитывая временно́е и географическое распространение сохранившихся версий, этот вопрос прямо напрашивается. Я полагаю, что несмотря на некоторые текстовые отклонения, на него можно ответить положительно: эти отклонения не выходят за рамки обычных расхождений. Фонетические различия естественны, они свидетельствуют о языковом развитии и проникновении изменений в церковнославянский язык, а также о различных языковых явлениях в тех областях славянского мира, где МСГ переписывалась. Таким же образом более старые морфологические формы заменялись более новыми. В противовес этому синтаксический и лексический уровни демонстрируют относительную стабильность.

На текстуальном уровне можно найти различные модификации, часто встречаются пропуск и перегруппировка союзов и частиц. Некоторые разночтения являются результатом вполне объяснимых

${ }^{2}$ Выражаю искреннюю благодарность монахам Хиландарского монастыря, а также Центру медиевистских славянских исследований Государственного университета Огайо, в особенности М. Джонсон, за то, что она любезно предоставила мне снимки рукописи.

${ }^{3}$ Снимки этой рукописи мне любезно предоставил коллега Ф. Чайка. Я чрезвычайно благодарен ему за это исключительное проявление коллегиальности. 
исправлений при переписывании, в качестве примера приведём пассаж, включающий категории святых, к которым обращается молящийся $(\mathrm{J} 78 \text { a } 10-17)^{4}$ :

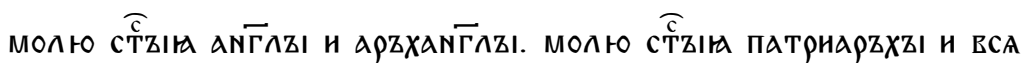

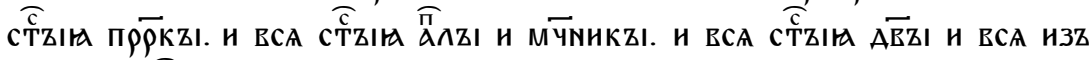

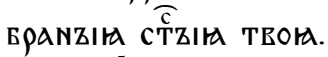

- лат. ${ }^{5}$ Precor $s(a n) c(t)$ os angelos et archangelos tuos. Precor om(ne)s s(an)c(t)os patriarchas et p(ro)phetas et om(ne)s apostolos et martyres et confessores et virgines et om(ne)s s(an)c(t)os et electos tuos.

Здесь рукопись D отличается от всех остальных версий добавле-

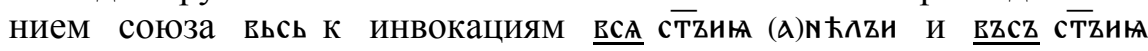
патрнархzи, после категории мучеников прибавляются нсповъаьмнкън н постZNнкZи. «Исповедующие» (нсповЂАьмнцин) приведены и в версиях $\mathrm{M}, \mathrm{S}, \mathrm{H}, \mathrm{P}$ и R (что соответствует большинству вариантов латинского оригинала), рукопись Р добавляет еще и феминитив (нзповєАлнки и нзповєАкицы). В прочих вариациях мы также находим логически обоснованные исправления, например, рукопись $R$ изменяет очерёдность ангелов и архангелов, рукописи $\mathrm{M}, \mathrm{S}$ и $\mathrm{H}$ после инвокации к святым девам добавляют пассаж молю и прнзвівањ, эти же рукописи одинаковым образом меняют порядок слов в заключительной части цитируемого отрывка, в них мы читаем твоА изБьрАлнА, в рукописях $\mathrm{P}$ и $\mathrm{R}$ пропущены пророки, рукопись Р вдобавок пропускает категории патриархов и ангелов.

Подобные разночтения демонстрируют и варианты исходного латинского текста, где добавляются или наоборот пропускаются место-

4 Здесь и далее я цитирую молитву по основному тексту согласно версии из Ярославского сборника (издание см. в Vepřek 2013: 108-131) с разночтениями из $\mathrm{M}$, варианты $\mathrm{H}, \mathrm{P}$ и $\mathrm{R}$ по снимкам рукописей, версию $\mathrm{S}$ по изданию Ф. Чайки (2014), а вариантный текст D по фототипическому изданию (Miklas et al.: 2012) в транслитерации из глаголицы в кириллицу.

5 Латинский текст приводится согласно изданию (Vepřek 2013: 108-131), которое основывается на тексте рукописи b 9 монастыря в городе Тепла, в случае разночтений в вариантных рукописях приведены их источники. 
имения и прилагательные (omnes, tuus, sanctus) и союз et ${ }^{6}$. В целом можно эту вариативность латинских и церковнославянских версий приписывать сравнительно свободным исправлениям в неканонизированном тексте, которые могли быть введены независимо от звучания протографа - таким образом, для подробного текстологического исследования, направленного на реконструкцию филиации рукописей, это мало релевантно.

Намного большее значение мы придаем тому факту, что перед этим пассажем в церковнославянской версии добавлена сравнительно пространная инвокация к Деве Марии, в J (78a 7-9) в следующем ви-

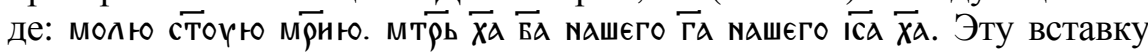
с мелкими модификациями содержат также версии M, S, H, R и P, только версия D точно отражает звучание латинского оригинала, где на этом месте обращение к Деве Марии отсутствует. Это одно из важных свидетельств того, что версия D представляет самостоятельную рукописную традицию, в то время как остальные варианты выводятся из отличающегося архетипа.

Также важным фактом является отражение идентичной ошибки писца (?) в пассаже нжє юсть прнспо вєс покона и БєЗZ свБта - и нє нмZІ власти (J, 76b, 16-18) - lat. qui semp (er) e(st) sine refrigerio. et sine splendore. et sine dulcedine est. Здесь вместо ожидаемого существительного *сласть, которое соответствовало бы латинской форме dulcedo, мы встречаем власть. Версия D не содержит этого пассажа, поэтому её нельзя включить в сравнение. Наоборот, так же, как и в версии J, в S, H, Р и R мы находим существительное власть. В версии M весь пассаж сокращен, в ней мы читаем только н кє имћж комца. Можно предположить, что версия М отражает более позднее исправление, устранившее искажненное место. На основании этой аргументации очевидно существование общего архетипа трех русскоцерковнославянских и двух сербскоцерковнославянских версий молитвы.

Теперь перейдем к специфике отдельных церковнославянских вариантов в сравнении с общим текстологическим разбором МСГ. В связи с вопросом происхождения перевода молитвы, конечно, кажется очень важной характеристика двух сербскоцерковнославянских списков.

\footnotetext{
${ }^{6}$ Обзор латинских вариантов см. в издании (Vepřek 2013: 127).
} 
В общем можно сказать, что обе версии показывают ряд схождений, в том числе в случае мелких инноваций в тексте; то есть это две самые близкие друг к другу версии во всем контексте изучаемых вариантов. Например, в вышеприведенном отрывке с искажением *сласть > власть следует пассаж и юсть вєс копьца (Ј, 76b 19). В обоих рукописных версиях $\mathrm{S}$ и $\mathrm{H}$ мы находим одинаковое разночтение и кє имы ком'ца. Это также прекрасно иллюстрирует отношение этих сербскоцерковнославянских версий к варианту М, поскольку здесь можно отметить явную связь с вариантом и кє нмъх комца, приведенным выше. Еще более значительным доказательством связи версий $\mathrm{S}$ и Н является вариант к пассажу мє зА мою мєАостонмєство (J 76b 1011), где обе упомянутые версии одинаково заменяют существительное NєАостонньство антонимом Аостонмьство (в идентичном написании Ао̆нство). Наконец, того же типа разночтение пассажа нко к踣

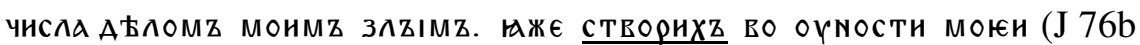
1-4). Рукописные версии $\mathrm{S}$ и $\mathrm{H}$ здесь добавляют к глагольной форме отрицание - Nє сътвори. Таким образом, мы можем сделать промежуточный вывод о том, что сербскоцерковнославянские версии молитвы исходят из общего протографа, который в южнославянскую среду попал с Руси (cp. С̆ajka 2014). Из остальных церковнославянских версий он был ближе всего к варианту из рукописи $\mathrm{M}$, как свидетельствуют некоторые общие более поздние изменения текста, например в отрывке прнгвозАнвъ са ㅅ арєвъ (J 76b8-9) М, S и Н добавляют прилагательное крьстьNZ (то есть NA Арєвђ крьстьмБмь), что мы на основании латинской параллели posuisti te in ligno, не имеющей прилагательного будем считать поздней вставкой.

В обеих русскоцерковнославянских версиях $\mathrm{P}$ и $\mathrm{R}$, напротив, есть соответствия некоторым важным разночтениям, сохранившимся в рукописи Ј. Это относится, например, к звучанию «рубрики», то есть данных о посвящении и цели молитвы. Здесь в первую очередь важен вариант R, который соответствует звучанию J практически дословно, за исключением некоторых орфографических/фонетических и морфологических вариантов и добавления существительного папа после имени грнгорнн. Соответствие относится и к некоторым деталям, например, во введении молитвы в J мы читаем пассаж накожє змағо АзZ врБмА мою влнзь соүщє (J 74a16-18). В версиях М, S и Н пропущено притяжа- 
тельное местоимение мою, в то время как в $\mathrm{P}$ и $\mathrm{R}$ оно сохраняется, что соответствует звучанию латинского оригинала - quia iam cognosco te(m)p(us) $\underline{m e u(m)} p($ rop)e e(ss)e. Еще более выразительное соответствие мы находим в отрывке, переводящем лат. Et in quacumq(ue) die invocavero te velocit(er) exaudire me digneris. Пассаж $\mathrm{J}$ (75b1-3) вопьжє колижао АЙь Прнзовоү та скоро оүслъіши ма соответсвует версиям Р и $\mathrm{R}$, в то время, как разночтения из рукописей $\mathrm{M}, \mathrm{S}$ и Н заменяют этот фрагмент на более позднее въсхощи вслышшати ма. Далее также в пас-

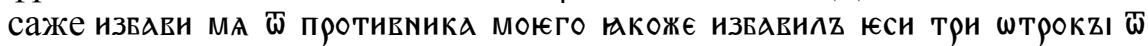
пєџи шгNєNZIњ. (J 75a19-75b4) в соответствии с версией J в $\mathrm{P}$ и R не названы три отрока в печи огненной (M, S и H называют в соответствиИ с ЛатинсКИм ориГИНаЛом СЕАРАХА, мнсаХА и АвАєNАГО).

В то же время можно проследить, что некоторые индивидуальные отклонения или искажения версии J в P и R не отражены, например, искажение глагола ожєстити сA в пассаже нако шстнлz юси сАЦЕ мою нко и камєNь. (Ј 75b 8-11). Вариантные чТения из рукоПисей $\mathrm{P}$ и $\mathrm{R}$ здесь содержат глагол ожєсточати са в виде ожєсточало са юсть. Более значим тот факт, что версии $\mathrm{M}, \mathrm{S}$ и $\mathrm{H}$ единообразно отражают другой словообразовательный вариант - ожєстило сА юсть.

Определение точного места версии D в текстологической схеме проблематично, поскольку, как уже выше было констатировано, в D не сохранился полный текст МСГ, а лишь приблизительно последняя треть. Тем не менее, некоторые важные факты начинают проясняться. Неудивительно, что D сохраняет такие более архаичные языковые элементы, как, например, супин или адноминальный датив (ср. Stankovska 2016: 386). В стилистическом плане версия D подтверждает употребление гендиадиса, добавляя еще один пример этой стилистической фигуры - кротокz и мнлосрzдz, чему в J соответствует Пассаж вүАн мн кротокъ (J 77b 1-2) в соответствии со всеми остальными более поздними церковнославянскими версиями. Напротив, два других примера гендиадиса, единообразно представленных в остальных церковнославянских версиях, в D мы не находим, хотя, как констатирует П. Станковска (Stankovska 2016: 385), нельзя исключать, что в первоначальном переводе они были. В случае некоторых вариантов из D нельзя однозначно решить, отражают ли они первоначальный текст перевода. Это относится, например, к пассажу, в 
котором в Ј мы читаем излћи ш шчню моєю слєзъ (J 77b 5-6) в соответствии с остальными церковнославянскими версиями, кроме $\mathrm{D}$, в которой представлено беспредложное словосочетание - изльи очнма монма слzзzн. Вариант из D, кажется, лучше соответствует латинскому протографу в большей части изученных текстовых версий effunde oculis meis lacrimas, однако и здесь в некоторых рукописях мы находим разночтение effunde ex oculis meis lacrimas. Наоборот, с большой степенью правдоподобности в D первоначальное звучание

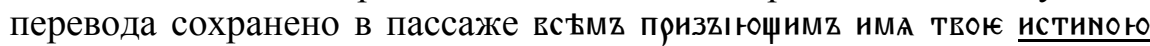
(J 78b13-15), где в D вместо формы истимоно (в версиях M, S, H и R представлен Вин. п. ср. рода прилагательного нстиммоє) использована предложная конструкция въ истимж, полностью соответствующая фрагменту из латинской параллели omnibus invocantibus nomen tuum in veritate.

Рассмотрев все варианты церковнославянского текста МСГ, можно прийти к следующей филиационной схеме:

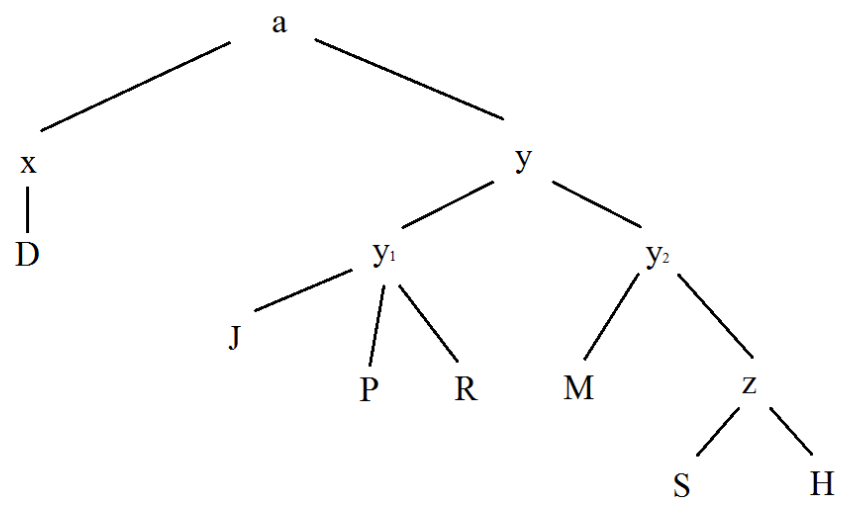

Пояснения к схеме:

a - гипотетический архетип;

$\mathrm{x}, \mathrm{y}, \mathrm{z}$ - гипотетические частичные протографы;

$\mathrm{D}, \mathrm{J}, \mathrm{P}, \mathrm{R}, \mathrm{M}, \mathrm{S}, \mathrm{H}$ - сокращения рукописных версий молитвы. 
Ни в предшествующий анализ, ни в схему намеренно не был включен пассаж МСГ, сохранившийся в качестве цитаты в тексте Молитвы к святой Троице (далее Trin). Этот пассаж слишком краток, чтобы можно было точнее установить её текстологические связи в рамках всей текстовой традиции МСГ. Подробный анализ цитаты из МСГ в Trin провел Т. Микулка (Mikulka 2015: 374-376), который обратил внимание на один очень важный факт: цитата содержит также краткий пассаж, который не опирается ни на одну из до сих пор известных латинских параллелей, и, как кажется, является оригинальной вставкой переводчика/автора МСГ. Речь идет о следующем отрывке (Jar 75b 12):

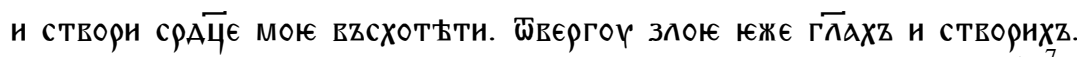

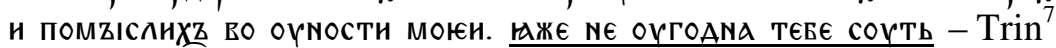

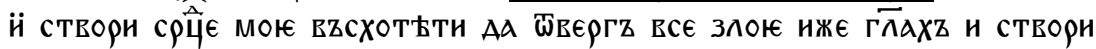
XZ Н ПОМZICAHXZ BZ OYNOCTH MOЮН HАЖE NE OYГOAHAZ БYAY TEББ.

Хотя здесь можно отметить морфологическую разницу (Микулка в цитируемой статье также рассуждает о чешскоцерковнославянских особенностях употребления так называемого futurum exactum), однако мы согласны с гипотезой, в соответствии с которой таким образом можно подтвердить тот факт, что цитата из Trin является следствием знакомства с рассматриваемой версией МСГ.

Анализ Т. Микулки можно дополнить одним вариантным разночтением из недавно найденной версии из рукописи $\mathrm{R}$, которое он в свое исследование включить не мог. Речь идет о разнице между формами отвергоү из МСГ (все вариантные церковнославянские рукописи, по-видимому, подтверждают, что в первоначальном варианте присутствовал союз АА, то есть АА отвєргоү) и АА отвєрГъ из Trin. К этой форме из Trin (1-е л. ед. ч. асигматического аориста или им. п. ед. ч. действит. причастия прошедшего времени) очень близка форма АА ๘вєр孔z, засвидетельствованная в версии R.

${ }^{7}$ Пассаж цитируется по рукописи Sin согласно работе Микулки (Mikulka 2015: 375). 


\section{Выводы:}

1. После изучения пяти версий церковнославянского перевода МСГ в дополнение к двум, которые были рассмотрены в предыдущей работе (см. Vepřek 2013), можно констатировать, что все рукописные варианты славянского перевода МСГ исходят из одного архетипа.

2. Церковнославянский текст МСГ очевидно переведен с латинского оригинала, однако ни одну из почти сорока известных к настоящему моменту латинских рукописей нельзя идентифицировать как непосредственный протограф славянского перевода. Вместе с тем включение новых церковнославянских вариантов не поколебало установленного факта, что латинские рукописи, наиболее близкие к славянскому тексту, относятся главным образом к XI веку.

3. Самая старая сохранившаяся версия из так называемой Дмитриевой псалтыри позволяет уточнить временну́ю вилку датировки перевода, который, таким образом, должен был возникнуть самое позднее в течение XI века (скорее всего, в его первой половине). Вскоре после этого выделились две основные текстовые традиции, к которым можно свести филиационную схему отдельных рукописных вариантов.

4. Гипотезу о западнославянском происхождении архетипа церковнославянского перевода МСГ можно по-прежнему считать самой правдоподобной.

\section{ЛИТЕРАТУРА}

Бычков 1880 - Бычков А. Ф. Описание славянских и русских рукописных сборников Императорской публичной библиотеки. СПб.: Типография Императорской Академии наук, 1880.

Соболевский 1905 - Соболевский А. И. Несколько редких молитв из русскаго сборника XIII века. Известия отделения русского языка и словесности Академии наук. 1905. Т. 10. Вып. 4. С. 66-78.

Станков 2016 - Станков Р. Древнеболгарские переводные тексты и проблема лексических моравизмов. София, 2016.

Čajka 2014 - Čajka F. Srbskocírkevněslovanský rukopis Modlitby sv. Řehoře // Kouřil (ed.). Cyrilometodějská misie a Evropa - 1150 let od příchodu soluňských bratř́i na Velkou Moravu. Brno, 2014. S. 288-292. 
Čermák 2014 - Čermák V. [rec.:] Vepřek M. Modlitba sv. Řehoře a Modlitba vyznání hříchů v církevněslovanské a latinské tradici. Olomouc, 2013 (Studia mediaevalia bohemica 6. 2014. S. 119-126).

Mareš 1979 - Marě̌ F. V. An Anthology of Church Slavonic Texts of Western (Czech) Origin. München, 1979.

Miklas et al. 2012 - Miklas H. et al. Psalterium Demetrii Sinaitici (monasterii sanctae Catharinae codex slav. 3/N): adiectis foliis medicinalibus. Wien, 2012.

Mikulka 2015 - Mikulka T. Ke genezi církevněslovanské Modlitby ke svaté Trojici // Slavia. 2015. Roč. 84. S. 372-396.

Stankovska 2016 - Stankovska P. Některé překladové a jazykové prvky nejstaršího známého opisu části Modlitby sv. Řehoře v hlaholském Dimitrijově Žaltáři // Янакиева И. (ed.). Quadrivium: юбилеен сборник в чест на 60годишнината на проф. д-р Веселин Панайотов. Шумен, 2016. С. 383-389.

Vepřek 2013 - Vepřek M. Modlitba sv. Řehoře a Modlitba vyznání hříchů v církevněslovanské a latinské tradici. Olomouc, 2013.

(Перевод М. Н. Саенко)

\author{
Miroslav Vepřek \\ Palacký University Olomouc, Czechia
}

\title{
On the Recently Discovered Versions of the Church Slavonic Prayer of St. Gregory
}

The section presents an analysis of the newly found Church Slavonic versions of the so-called Prayer of St. Gregory. The prayer was translated from Latin and its complete text was preserved in six manuscripts in Russia and Serbia. The oldest part of the prayer - precisely the last third of the prayer - was written in the manuscript of Dimitri's Psalter, which was discovered in 1975 in the monastery of St. Catherine on Mount Sinai. The analysis confirms that all the versions were derived from the same archetype whilst the two basic branches of the textual tradition split no later than in the 11th century. According to the presented research, West Slavonic origin of the translation is still the most probable; a short quotation of the prayer documented in Prayer to the Holy Trinity (another Church Slavonic paraliturgical text of Czech origin) serves as the evidence that the observed literary monument was well known and used in Bohemia in the 11th century.

Key-words: Church Slavonic, prayer, paraliturgical texts, Prayer of St. Gregory 